\title{
Reactive Infiltration of TiN Powder Preform with Molten Aluminum for the Fabrication of Nitride Ceramics Composite
}

\author{
Yoshihiro Kobayashi*, Makoto Kobashi and Naoyuki Kanetake \\ Department of Materials Science and Engineering, Graduate School of Engineering, Nagoya University, \\ Nagoya 464-8603, Japan
}

Reactive infiltration of a blended powder preform containing TiN with molten aluminum was attempted at temperatures ranging from $1173 \mathrm{~K}$ to $1673 \mathrm{~K}$ in order to fabricate nitride ceramics composite. Titanium powder as an infiltration aid was mixed with TiN powder (particle sizes: $53 \mu \mathrm{m}$ and $1.0 \sim 1.5 \mu \mathrm{m}$ ) by various blending ratios. Spontaneous infiltration of the blended powder with molten aluminum occurred on condition that processing temperature and titanium content in the blended powder were high enough. Spontaneous infiltration took place when processing temperature was $1673 \mathrm{~K}(\mathrm{TiN}: 53 \mu \mathrm{m})$ or processing temperature was over $1173 \mathrm{~K}(\mathrm{TiN}: 1.0 \sim 1.5 \mu \mathrm{m})$. It was confirmed that $\mathrm{Al} \mathrm{T}_{3} \mathrm{Ti}$ and TiN were the main constituents after the infiltration was completed. SiC whisker was added in the blended perform powder (TiN: $1.0 \sim 1.5 \mu \mathrm{m}$, Ti: $<45 \mu \mathrm{m})$ by various blending ratios $(4 \sim 30 \mathrm{vol} \%)$. The results showed that SiC whiskers were successfully dispersed by up to $10 \mathrm{vol} \%$ in the $\mathrm{Al}_{3} \mathrm{Ti} / \mathrm{TiN}$ ceramics composite. [doi:10.2320/matertrans.L-MRA2008812]

(Received November 6, 2007; Accepted March 7, 2008; Published June 25, 2008)

Keywords: titanium nitride, in-situ process, reactive infiltration, pressure-less infiltration

\section{Introduction}

Pressureless infiltration process as one of the fabrication methods of metal matrix composites (MMCs) is attractive on account of the following aspects. ${ }^{1-4)}$

- Cost-effective process

- Near net shape production

- High volume fraction of ceramic reinforcements

Good wettability between a solid powder phase and a liquid metal is required to realize the spontaneous infiltration process. The good wetting condition is often defined by a low contact angle $\left(<90^{\circ}\right)$ of the sessile droplet test. ${ }^{5,6}$ Nonwetting metal/ceramics combination makes the penetration of molten metal into the particle perform difficult. We have reported the effectiveness of blending the reactive elemental powders with ceramics reinforcements to realize the spontaneous infiltration (reactive infiltration). ${ }^{7-10}$ ) The reactive powder increases the peripheral temperature when contacts with molten metal, and improves the wettability. This process can provide a continuous ceramic or intermetallic matrix composite since the ceramics or intermetallics are synthesized in situ. ${ }^{4}$

The wettability between titanium nitride (TiN) and aluminum is reported to be poor, although $\mathrm{TiN}$ is an attractive ceramics on account of high hardness, excellent stability at high temperatures, good electrical and optical properties, good thermal conductivity. ${ }^{11)}$ The combination between titanium and molten aluminum is highly reactive and can be applied to the reactive infiltration technique. ${ }^{12)}$ Therefore, by using titanium as the infiltration aid, the spontaneous infiltration of a titanium nitride (TiN) and titanium blended powder preform with molten aluminum can be expected. The schematic illustration of reactive infiltration process investigated in this experiment is shown in Fig. 1. By the reaction between titanium and aluminum (eq. (1)), $\mathrm{Al}_{3}$ Ti matrix is synthesized.

*Graduate Student, Nagoya University

$$
\mathrm{Ti}+3 \mathrm{Al}=\mathrm{Al}_{3} \mathrm{Ti}+146 \mathrm{~kJ}
$$

With the help of the reactive infiltration technique, it can also be expected to disperse whiskers in the composite by simply blending whiskers in the powder perform. Since squeezing pressure is not necessary, physical damage to the whisker can be minimized. Such hybrid metal matrix composites are reported to bring the combined advantages of both whisker and particles, and also provides a variation in mechanical properties such as creep resistance. ${ }^{13,14)}$

In this study, effect of processing parameters (processing temperature, powder perform composition, TiN powder size, silicon carbide whisker addition to perform powder) on the infiltration capability and microstructure are investigated.

\section{Experimental Procedure}

\subsection{Preparation of nitride ceramics composite}

Two kinds of TiN powders (particle sizes: $1.0 \sim 1.5 \mu \mathrm{m}$ and $53 \mu \mathrm{m})$ and titanium powder (size: $<45 \mu \mathrm{m}$ ) were used as starting materials. Titanium powder was blended with TiN powder by various molar blending ratios (TiN/Ti molar blending ratio: $0.5 \sim 19.0$ ). This will be described as the $[\mathrm{Ti}+\mathrm{TiN}]$ blended powder in the following sections. During machine blending, large TiN powder $(53 \mu \mathrm{m})$ was crushed and become smaller $(7 \sim 8 \mu \mathrm{m})$. The size of smaller TiN $(1.0 \sim 1.5 \mu \mathrm{m})$ was not significantly affected by machine blending. The $[\mathrm{Ti}+\mathrm{TiN}]$ blended powder $(4.0 \mathrm{~g})$ was compacted under a pressure of $200 \mathrm{MPa}$ to make a preform (porosity: 35 45\%). The shape of the preform was columnar and its diameter and height were $10 \mathrm{~mm}$ and $15 \mathrm{~mm}$, respectively. The preform was located at the bottom part of an alumina $\left(\mathrm{Al}_{2} \mathrm{O}_{3}\right)$ crucible, and a pure aluminum ingot (6 g, purity: $99.9 \%$ ) was placed on the preform as shown in Fig. 2. The specimen was then heated up to a processing temperature $(1173 \mathrm{~K} \sim 1673 \mathrm{~K})$ by an induction furnace in $\mathrm{N}_{2}$ gas atmosphere. The average heating rate to the 

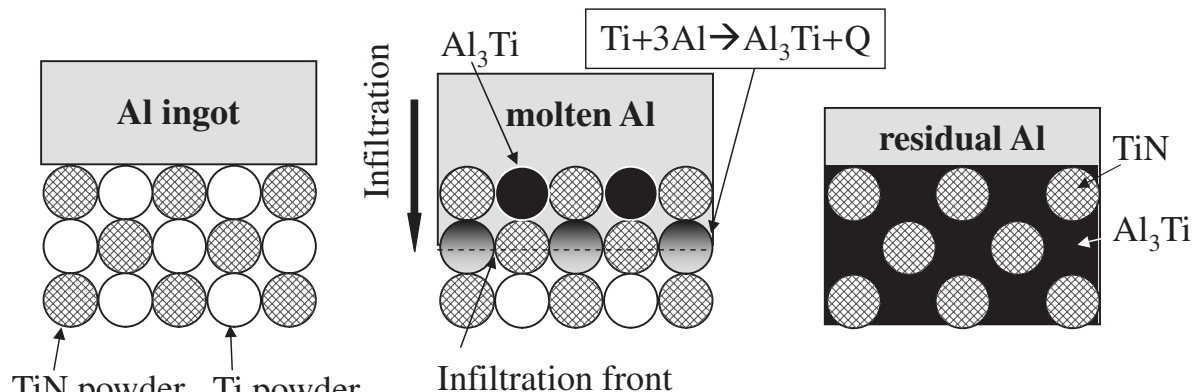

TiN powder Ti powder

Infiltration front
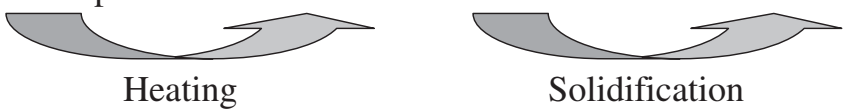

Fig. 1 Schematic illustration of reactive infiltration of [TiN+Ti] powder preform with molten aluminum.

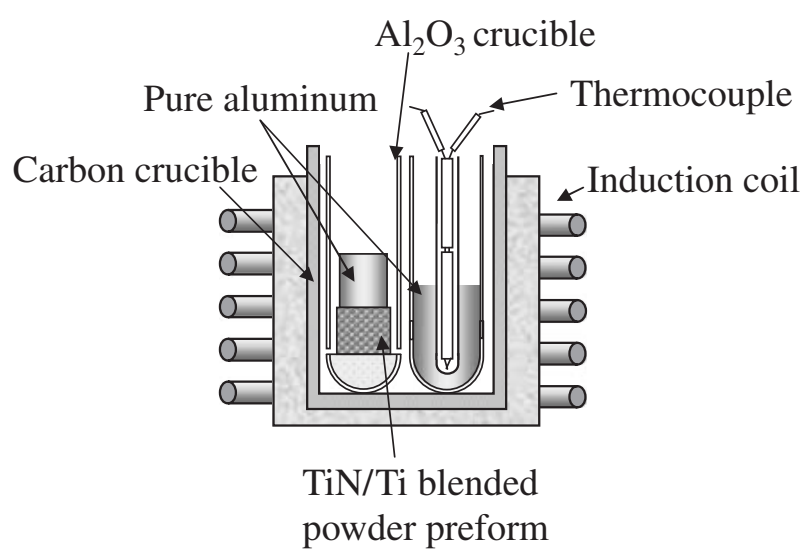

Fig. 2 Schematic illustration of the experimental set-up.

processing temperature was $20 \mathrm{~K} / \mathrm{min}$. The specimen was cooled down in the furnace after reaching at the processing temperature.

\subsection{Preparation of $\mathrm{SiC}$ whisker composites}

$\mathrm{SiC}$ whisker $(10 \sim 15 \mu \mathrm{m}$ in length, $0.6 \sim 0.8 \mu \mathrm{m}$ in diameter) was added to the $[\mathrm{Ti}+\mathrm{TiN}]$ blended powder (TiN: $1.0 \sim 1.5 \mu \mathrm{m}$, Ti: $<45 \mu \mathrm{m})$ by various volume fractions ranging from $4 \%$ to $30 \%$. The powders and whisker were mixed in ethanol for 30 minutes, and dried in an electronic oven at $373 \mathrm{~K}$ for 5 hours. The blended materials were compacted under a pressure of $200 \mathrm{MPa}$ to make the preform (porosity: 40 50\%). The blended preform and a pure aluminum ingot $(6 \mathrm{~g}$, purity: $99.9 \%$ ) were heated together up to $1173 \mathrm{~K}$ by the induction furnace in $\mathrm{N}_{2}$ gas atmosphere.

\subsection{Analysis of microstructures}

The vertical cross sections of the specimens were observed by scanning electron microscope (SEM). The quantitative analysis of the specimen was carried out by energy dispersive $\mathrm{X}$-ray analysis (EDX) and X-ray diffraction analysis (XRD).

\section{Results}

\subsection{Effect of the processing temperature and $\mathrm{TiN} / \mathrm{Ti}$ powder blending ratio}

Processing temperature and TiN/Ti blending ratio are the important parameters which determine the possibility of spontaneous infiltration. Figure 3 shows vertical cross sections of specimens (TiN/Ti ratio: (a) 8.0, (b) 19.0 and (c) 0.93 , TiN size: $53 \mu \mathrm{m}$ ) fabricated at $1673 \mathrm{~K}$ as typical examples of complete infiltration, incomplete infiltration and porous microstructure. The bottom half (dark part) is the infiltrated composite and the upper half (bright part) is the residual aluminum which did not penetrate into the preform.
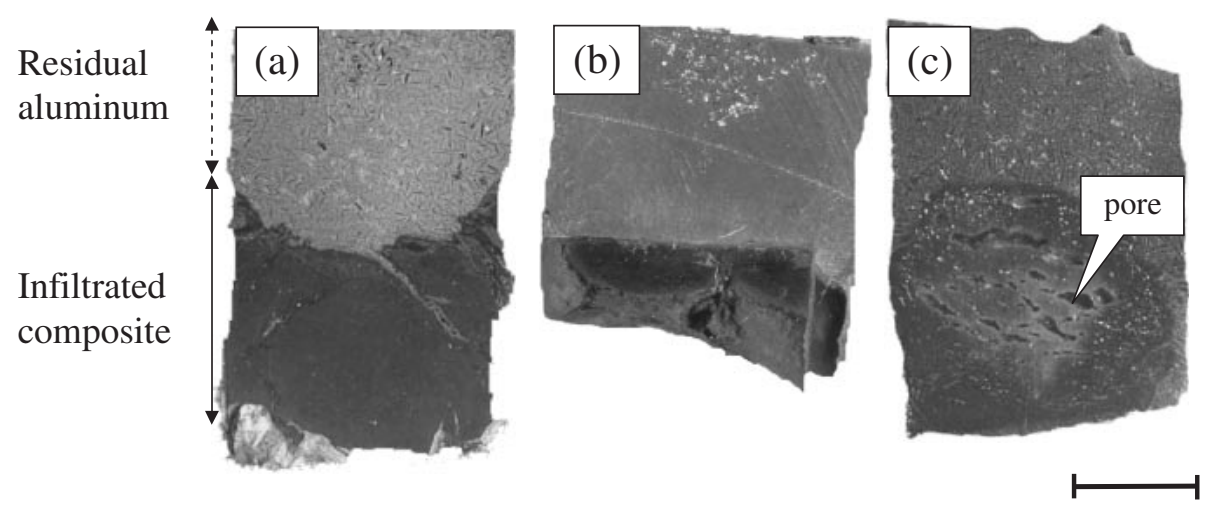

$5 \mathrm{~mm}$

Fig. 3 Vertical cross section of the specimens fabricated at $1673 \mathrm{~K}$, showing (a) complete infiltration (TiN/Ti=8.0), (b) incomplete infiltration $(\mathrm{TiN} / \mathrm{Ti}=19.0)$ and $(\mathrm{c})$ porous structure $(\mathrm{TiN} / \mathrm{Ti}=1.0)$. 
Table 1 Possibility of spontaneous infiltration under various processing conditions (processing temperature: $1273 \mathrm{~K} \sim 1673 \mathrm{~K}$, molar TiN/Ti blending ratio: $0.5 \sim 20.0$ ).

\begin{tabular}{|c|c|c|c|c|c|c|c|c|c|}
\hline & & \multicolumn{8}{|c|}{ Molar blending ratios of $\mathrm{TiN} / \mathrm{Ti}$} \\
\hline & & 0.5 & 0.93 & 5.0 & 8.0 & 9.0 & 15.0 & 19.0 & 20.0 \\
\hline \multirow[t]{3}{*}{ Processing temperature } & $1273 \mathrm{~K}$ & $\triangle$ & $\triangle$ & $\triangle$ & $x$ & $\times$ & $x$ & - & - \\
\hline & $1473 \mathrm{~K}$ & $\triangle$ & $\triangle$ & $\triangle$ & $x$ & $x$ & $x$ & - & - \\
\hline & $1673 \mathrm{~K}$ & - & 0 & 0 & 0 & $\bigcirc$ & 0 & $\triangle$ & $x$ \\
\hline
\end{tabular}

$\bigcirc$ : Complete infiltration $\triangle$ : Incomplete infiltration $x$ : No infiltration -: No data

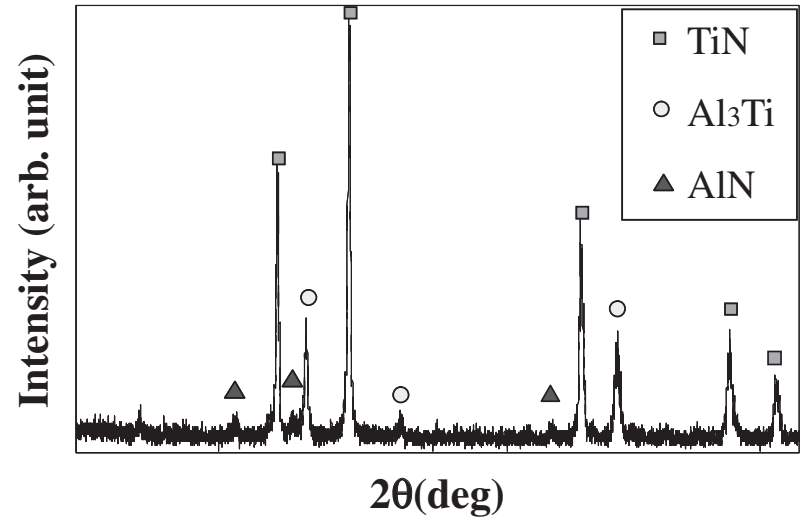

Fig. 4 XRD pattern of the infiltrated composite with a molar TiN/Ti blending ratio of 9.0 (processing temperature: $1673 \mathrm{~K}$ ).

The boundary between composite and residual aluminum was firmly bonded. When molar blending ratio of TiN/Ti was high, spontaneous infiltration stopped before reaching at the bottom of the preform as shown in Fig. 3(b). When molar blending ratio was low, many pores $(0.1 \sim 1 \mathrm{~mm})$ generated by the expansion of the preform was confirmed (Fig. 3(c)). This is because the large amount of titanium addition raised the specimen temperature higher than an adequate level to maintain the original size of the precursor. ${ }^{7)}$

Table 1 shows the results of spontaneous infiltration under various processing conditions (processing temperature: 1273 1673 K, molar TiN/Ti blending ratio: 0.5 20.0). The size of TiN particle was fixed to $53 \mu \mathrm{m}$. At $1673 \mathrm{~K}$, infiltration occurred when the molar blending ratio of TiN/Ti was below 17.0. At temperatures below $1473 \mathrm{~K}$, complete infiltration of the $[\mathrm{Ti}+\mathrm{TiN}]$ preform with molten aluminum did not occur regardless of the TiN/Ti blending ratios. XRD analysis was carried out on the completely infiltrated specimen (TiN/Ti: 5.0), and the result is shown in Fig. 4. X-ray peaks of $\mathrm{TiN}$ and $\mathrm{Al}_{3} \mathrm{Ti}$ were detected at appropriate angular positions whereas no peaks of $\mathrm{Ti}$ were detected. SEM micrograph of the same specimen is shown in Fig. 5. From EDX analysis, it was conformed that the light gray matrix and the white particles in the figure were confirmed as $\mathrm{Al}_{3} \mathrm{Ti}$ and TiN, respectively. No residual titanium powder was visible. Therefore, the conversion of titanium to $\mathrm{Al}_{3} \mathrm{Ti}$ was confirmed. In Fig. 5, homogeneous distribution of $\mathrm{Al}_{3} \mathrm{Ti}$ without pore formation was observed. When molar blending ratio was not appropriately selected, extreme expansion of preform and pore formation (see Fig. 3(c)) took place. It is well-known that the reaction between titanium and aluminum is highly exothermic and $\mathrm{Al}_{3} \mathrm{Ti}$ as a reaction product tended

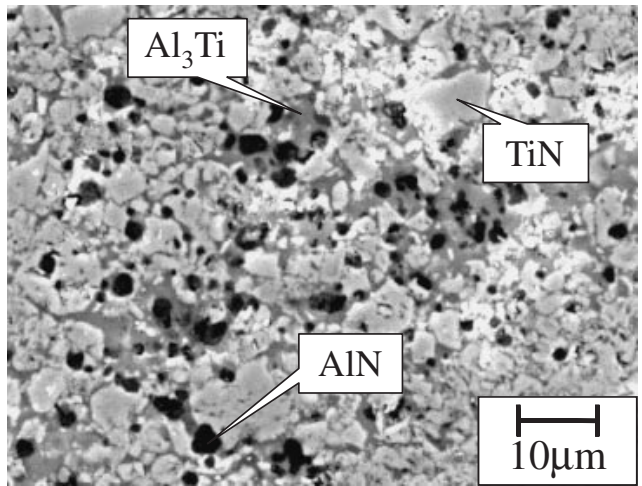

Fig. 5 Microstructure of the infiltrated composite with a molar TiN/Ti blending ratio of 9.0 (processing temperature: $1673 \mathrm{~K}$ ).

to expand and became porous. The sufficient amount of TiN in powder preform absorbed the heat of reaction and, therefore restrained such an extreme exothermic behavior. A minute quantity of AlN formation was also confirmed as shown by the black spots in Fig. 5. AlN is known to possess high melting temperature, good resistance to thermal shock due to its high thermal conductivity, and stability in the presence of molten aluminum, thus AlN ceramic is regarded as a candidate for high performance application. ${ }^{15,16)}$

\subsection{Effect of TiN particle size}

The TiN powder with a smaller size $(1.0 \sim 1.5 \mu \mathrm{m})$ was used to see how the TiN powder size affects the infiltration capability and the matrix microstructure. Figure 6 shows macro- and microscopic vertical cross sections of the specimens fabricated with $\mathrm{TiN} / \mathrm{Ti}$ molar ratio of 19.0 (processing temperature: $1173 \mathrm{~K}$ ). The results showed that the spontaneous infiltration took place at $1173 \mathrm{~K}$, which can not be achieved with $53 \mu \mathrm{m}$ TiN powders. Dispersion of fine TiN particles is identified in Fig. 6(b). The spontaneous infiltration was driven by the capillary force written by the following equation.

$$
P \propto \frac{(1-\varepsilon) \cos \theta}{d \cdot \varepsilon}
$$

Where $P$ is the capillary force $[\mathrm{N}], \varepsilon$ is the porosity of preform $[-], \theta$ is contact angle $\left[{ }^{\circ}\right]$ and $d$ is the average particle size $[\mathrm{m}]$. Hence the smaller particle diameter makes capillary force larger when the contact angle is less than 90 degrees. The adiabatic combustion temperatures during the infiltration as a function of $\mathrm{TiN} / \mathrm{Ti}$ blending ratio (initial temperature: $1173 \mathrm{~K}$ ) were calculated by the eq. (3). 

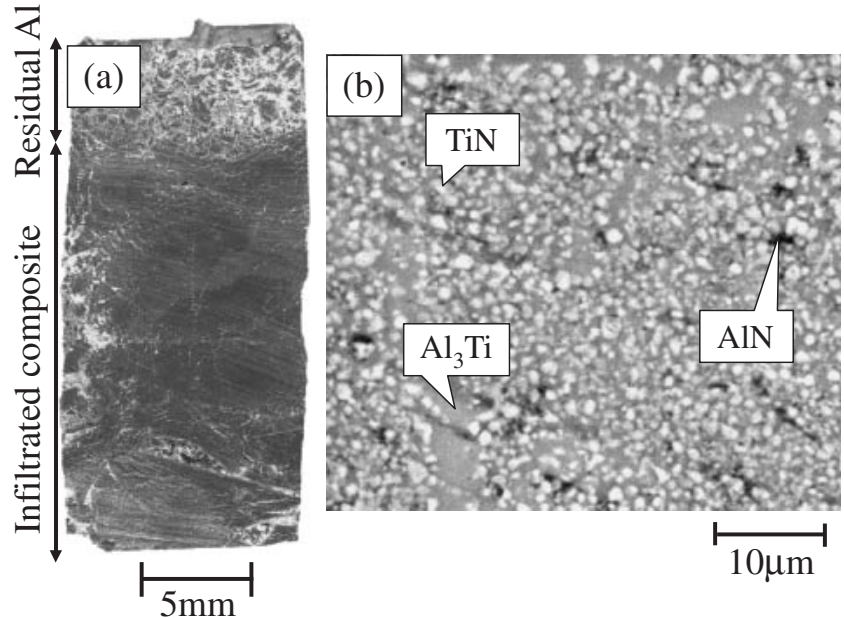

Fig. 6 (a) Macroscopic and (b) microscopic structures of an infiltrated composite fabricated at $1173 \mathrm{~K}(\mathrm{TiN} / \mathrm{Ti}: 19.0)$.

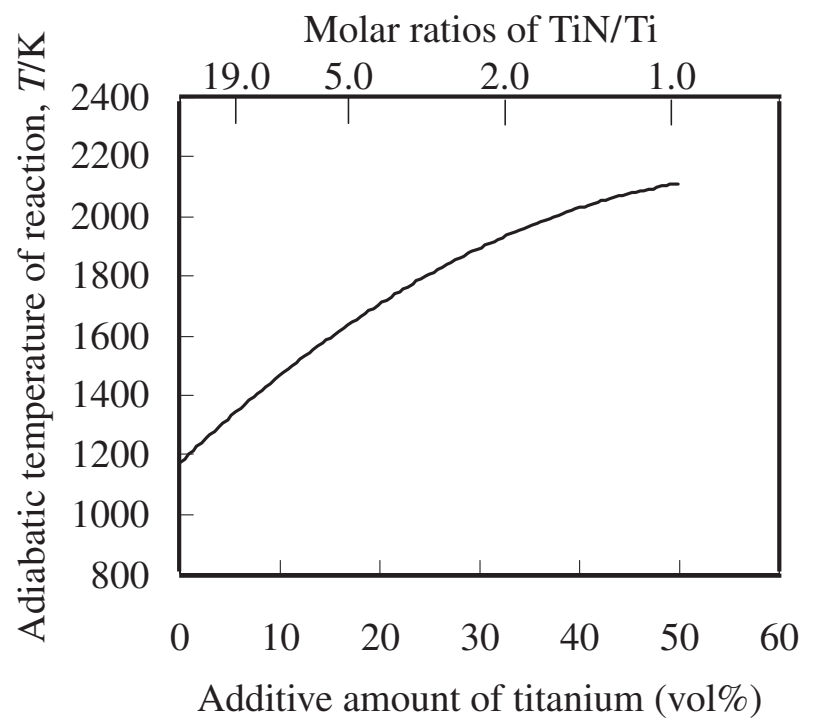

Fig. 7 Calculated adiabatic temperatures of the [TiN+Ti] blended powders and molten aluminum.

$$
3 \mathrm{Al}+\mathrm{Ti}+x \mathrm{TiN} \rightarrow \mathrm{Al}_{3} \mathrm{Ti}+x \mathrm{TiN}+\Delta H_{\mathrm{f}, \mathrm{Al}_{3} \mathrm{Ti}}
$$

$x$ : molar TiN/Ti blended ratios

$$
\Delta H_{\mathrm{f}, \mathrm{Al}_{3} \mathrm{Ti}}+x \int_{T_{0}}^{T_{\mathrm{ad}}} C_{\mathrm{p}, \mathrm{TiN}} d T+\int_{T_{0}}^{T_{\mathrm{ad}}} C_{\mathrm{p}, \mathrm{Al}_{3} \mathrm{Ti}} d T=0
$$

Fig. 7 shows the relation between the theoretical adiabatic combustion temperatures and titanium content, showing the steady temperature increase by increasing the titanium content. Wetting condition of the preform was adequately improved by the heat of reaction between molten aluminum and titanium. From this reaction, the contact angle between molten aluminum and TiN became below $90^{\circ}$ by a temperature increase. Moreover, the smaller TiN particle diameter makes capillary force more effective. Therefore, spontaneous infiltration was enhanced by using $1.0 \sim 1.5 \mu \mathrm{m}$ TiN powder.

\subsection{Fabrication of $\mathrm{SiC}$ whisker containing composites}

$\mathrm{SiC}$ whisker was added to the [TiN+Ti] powder perform (TiN: $1.0 \sim 1.5 \mu \mathrm{m}$ ) as describe in the former section, and the
Table 2 Possibility of spontaneous infiltration of the [TiN+Ti] powder preform containing SiC whisker (processing temperature: $1173 \mathrm{~K}$ ).

\begin{tabular}{cccccccc}
\hline & \multicolumn{7}{c}{ Volume fraction of SiC whisker (\%) } \\
\cline { 2 - 8 } TiN/Ti ratio & 0 & 4 & 8 & 10 & 14 & 30 \\
\cline { 2 - 8 } & 12.5 & $\bigcirc$ & $\bigcirc$ & $\bigcirc$ & $\bigcirc$ & $\triangle$ & $\triangle$ \\
\cline { 2 - 8 } & 15.0 & $\bigcirc$ & $\bigcirc$ & $\bigcirc$ & $\bigcirc$ & $\triangle$ & - \\
\cline { 2 - 7 } & 19.0 & $\bigcirc$ & $\bigcirc$ & $\triangle$ & $\triangle$ & - & - \\
\hline
\end{tabular}

$\bigcirc$ : Complete infiltration $\triangle$ : Incomplete infiltration - : No data
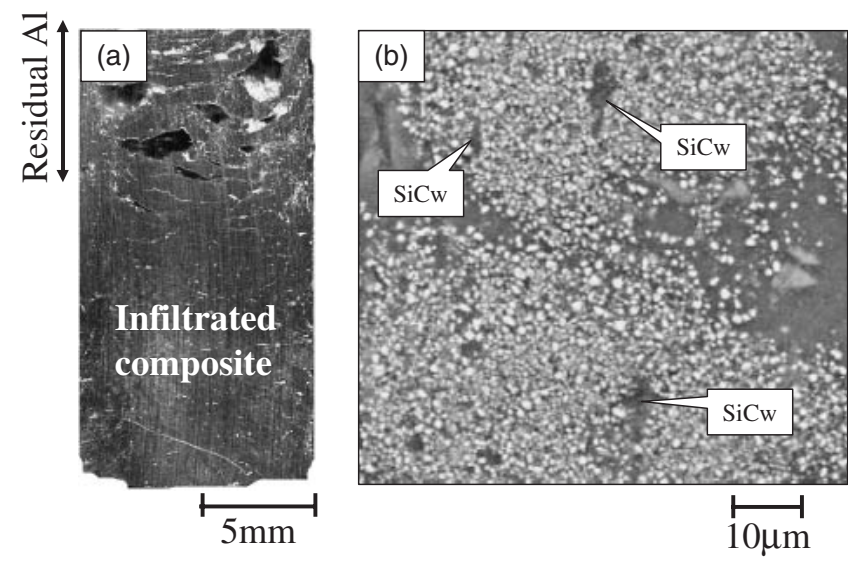

Fig. 8 Vertical cross sections of an infiltrated composite containing SiC whisker (TiN/Ti: 12.5, SiCw fraction: 8 vol\%) (a) macro section and (b) micro section.

possibility of spontaneous infiltration was observed. Table 2 shows the results of the possibility of spontaneous infiltration under various experimental conditions. Spontaneous infiltration took place when volume fraction of $\mathrm{SiC}$ was low. However, when volume fraction of $\mathrm{SiC}$ whisker increased to $14 \mathrm{vol} \%(\mathrm{TiN} / \mathrm{Ti}=12.5$ and 15.0$)$ and $8 \mathrm{vol} \%(\mathrm{TiN} / \mathrm{Ti}=$ 19.0), spontaneous infiltration could no longer be completed. It was revealed that decreasing the TiN/Ti ratio was effective to increase the limit of $\mathrm{SiC}_{\mathrm{w}}$ addition. Figure 8 shows (a) macroscopic and (b) microscopic vertical cross sections of a specimen containing $\mathrm{SiC}$ whisker (TiN/Ti: 12.5, $\mathrm{SiC}_{\mathrm{w}}$ fraction: 8 vol\%). In Fig. 8(a), complete infiltration was observed. In Fig. 8(b), it was conformed from spot analysis of $\mathrm{EDX}$ that the dark gray fibers were $\mathrm{SiC}_{\mathrm{w}}$. Homogeneous dispersion of $\mathrm{SiC}_{\mathrm{w}}$ in the matrix is seen in Fig. 8(b). Thus, it was revealed that the whisker dispersed composite can be fabricated without applying an external pressure by using the reactive infiltration technique.

\section{Conclusion}

Spontaneous infiltration of the $\left[\mathrm{Ti}+\mathrm{TiN}\left(+\mathrm{SiC}_{\mathrm{w}}\right)\right]$ powder blended preform with molten aluminum to fabricate nitride ceramics composite was attempted. The effects of processing parameters (processing temperatures, molar ratios of TiN/Ti and particle size of TiN) were investigated and the following results were obtained.

(1) Spontaneous infiltration of the blended powder preform (TiN size: $53 \mu \mathrm{m}$ ) with molten aluminum didn't occur when processing temperature was $1273 \mathrm{~K}$ or $1473 \mathrm{~K}$ even though blended ratio of titanium as infiltration aid 
was high enough. Spontaneous infiltration took place when processing temperature was $1673 \mathrm{~K}$ and molar ratio of TiN/Ti was less than 15.0.

(2) $\mathrm{Al}_{3} \mathrm{Ti} / \mathrm{TiN}$ composite was formed after the infiltration. Minute quantity of AlN was also observed.

(3) Pores were formed in the composite when molar ratio of TiN/Ti was low.

(4) Spontaneous infiltration occurred at $1173 \mathrm{~K}$ by using the smaller TiN powder $(1.0 \sim 1.5 \mu \mathrm{m})$.

(5) Spontaneous infiltration of the $[\mathrm{Ti}+\mathrm{TiN}]$ powder $(\mathrm{TiN}$ : $1.0 \sim 1.5 \mu \mathrm{m}, \mathrm{Ti}:<45 \mu \mathrm{m})$ containing $\mathrm{SiC}$ whisker was successfully occurred. The upper limit of $\mathrm{SiC}_{\mathrm{w}}$ fraction increased by decreasing the $\mathrm{TiN} / \mathrm{Ti}$ ratio. Maximum volume fraction of $10 \%$ was obtained without applying an external pressure to the melt by using the reactive infiltration process.

\section{REFERENCES}

1) S. Zhou, X. Zhang, Z. Ding, C. C. Min, G. Xu and W. Zhu: Compos. A38 (2007) 301-306.
2) S. Ren, X. He, X. Qu, I. S. Humail and Y. Li: Compos. Sci. Tech. 67 (2007) 2103-2113.

3) S. Ren, X. He, X. Qu, I. S. Humail and Y. Li: Mater. Sci. Eng. B 138 (2007) 263-270.

4) E. Candan: Mater. Lett. 60 (2006) 1204-1208.

5) J. V. Naidich: Prog. Surf. Memb. Sci. 14 (1981) 353-484.

6) A. R. Kennedy and A. E. Karantzalis: Mater. Sci. Eng. A264 (1999) 122-129.

7) T. Choh, T. Mohri and M. Kobashi: J. Mater. Proc. Tech. 63 (1997) 379-383.

8) M. Kobashi and T. Choh: J. Mater Sci. 32 (1997) 6279-6282.

9) N. Omura, M. Kobashi and N. Kanetake: J. Jpn. Inst. Met. 68 (2004) 211-215.

10) N. Omura, M. Kobashi and N. Kanetake: J. Jpn. Inst. Met. 68 (2004) 367-371.

11) A. K. Ray, K. Venkateswarlu, S. K. Chaudhury, S. K. Das and B. R. Kumar: Mater. Sci. Eng. A338 (2002) 160-165.

12) T. Y. Um and R. Watanabe: J. Jpn. Inst. Met. 58 (1994) 559-563.

13) A. Arunachaleswaran, et al.: Mater. Sci. Eng. A 460-461 (2007) 268-276.

14) K. H. Oh and K. S. Han: Compos. Sci. Tech. 67 (2007) 1719-1726.

15) M. Tajika, H. Matsubara and W. Rafaniello: Mater. Lett. 41 (1999) $139-144$.

16) J. Zhao, J. Gao and Z. Jin: Mater. Chem. Phys. 97 (2006) 506-510. 